\title{
TPDCV Regimen
}

National Cancer Institute

\section{Source}

National Cancer Institute. TPDCV Regimen. NCI Thesaurus. Code C10122.

A chemotherapy regimen consisting of thioguanine, procarbazine, mitolactol

(dibromodulcitol), lomustine, and vincristine that may be used in the treatment of malignant glioma. 